\title{
Modern Makroiktisadi Uzlaşının Kayıp Ekonomi Politiği: Yerleşik Formalist, Yerleşik Kuramsal ve Yerleşik Politik Uzlaşı
}

Selma Sevinç ORHAN, Department of Economics, Faculty of Economics and Administrative Sciences, Pamukkale University, Turkey; e-mail: sorhan@pau.edu.tr

\section{The Loss of the Political Economy of Modern Macroeconomic Consensus: Mainstream Formalist, Mainstream Theoretical and Mainstream Political Consensus}

\begin{abstract}
For the last three decades, the Mainstream macroeconomics has been witnessing a "theoretical consensus" between the New Classic Economics (NCE) and New Keynesian Economics (NKE). This consensus is a consensus of "New Classical Models" which are based on rational expectations and perfect markets assumptions and "New Keynesian Models" which are based on sticky wage, sticky prices and rational expectations assumptions, it is a "New Neo Classical Synthesis Economics". In this study, macro consensus discussion that stands out in the mainstream economics literature will be defined as "Mainstream Macro Theoretical Consensus", "Mainstream Formalist Methodological Consensus" and "Mainstream Macro Politics Consensus" and the performance of consensus economics will be discussed. Then, the dilemmas and weakness of mainstream methodology against crisis will be prioritized.
\end{abstract}

Keywords $\quad$ : New Classical and New Keynesian Consensus, Modern Macro Consensus, Keynes and Keynesian Revolution, DSGE Modells.

JEL Classification Codes : $\quad$ B25, B52, E12, E32.

Öz

Son otuz yıldır yerleşik makro iktisat yazını, Yeni Klasik İktisat (YKİ) ve Yeni Keynesyen İktisat (YK) arasındaki "kuramsal uzlaşıya" tanıklık etmektedir. Çağdaş modern makro iktisat yazını, rasyonel bekleyişler ve mükemmel piyasa varsayımları altında çalışan "Yeni Klasik Modeller" ile ücret-fiyat yapışkanlığı ve rasyonel bekleyişler varsayımlarıyla çalışan "Yeni Keynezyen Modelleri" buluşturan, "New Neo Klasik Sentez,"i kapsamaktadır. Çalışmada, yerleşik uzlaşı süreci "Yerleşik Kuramsal Uzlaşı", "Yerleşik Formalist Uzlaşı" ve "Yerleşik Politik Uzlaşı" olarak kavramsalaştırılmaktadır. Yerleşik makro uzlaşı iktisadının politik açmazları kuramsal ve metodolojik yönden analiz edilmektedir.

Anahtar Sözcükler $\quad$ : Yeni Klasik ve Yeni Keynezyen Uzlaşı, Modern Makro Uzlaşı, Keynes ve Keynezyen Devrim, DSGE Modelleri. 


\section{Giriş}

Görülen o dur ki, yerleşik modern makro uzlaşı iktisadı (yeni klasik ve yeni keynesyen sentez) gerek 2008 resesyonun ardında yatan dinamiklerin analizinde, gerekse küresel istikrarı sağlayan uluslararası kurumların mimarisinde gerekli ekonomi politik perspektifi ortaya koyabilecek bağlamın hayli dışındadır. Keynesyen uzlaşıdan günümüze, yerleşik iktisat yazınında süregelen uzlaşılarda, uzlaşan (sentezlenen) kuramlar arasında kendini gösteren varsayımsal tutarsızlıklarla birlikte, makroiktisat yazınının "yöntemsel uzlaşı" eğilimi dikkat çekicidir. Bu çalışmada, yerleşik makro uzlaşı iktisadında sentezlenen kuramlar arası varsayımsal faklılıklar vurgulanırken, öngörülebilirlik adına, yöntemsel tutarsızlık sorununun gözardı edildiği ortodoks yazında uğranan performans kaybı tartışılmaktadır. Yerleşik paradigmanın tüm uzlaşı deneyimlerinde, adhoc varsayımlarla göz ardı edilen, mikro ve makroiktisadi davranışsal kurumlar, piyasa süreçlerinde farklı iktisadi dinamikle gelişen, öngörülemez bir kurumsal ortam üretmekte, makro uzlaşı kuramlarının politika performansını zayıflatmaktadır. Yerleşik kuramda rasyonalite kaygısıyla kaybolan ekonomi politik söylem, küresel sistemde farklı formal ve informal kurumsal ortamların doğmasına yol açmakta, yeni iktidar ilişkileri üretmektedir. İktisat biliminin kapsayamadığ yeni bağlamlar, söylemler dünyası üretmektedir. Yerleşik iktisadın uzlaşırken neden olduğu kuramsal karmaşa, iktisat politikaları yoluyla ön görülemeyen, iktisat bilimi tarafindan çözümü hayli zorlaşan kurumsal bir evren yaratmaktadır.

Çalışmada, ilk uzlaşı deneyimi olarak, "Neoklasik Sentez Keynesyen İktisat”, o bağlamda sentezlenen "Neoklasikler ve J.Keynes” arasındaki ilişki tartışılmaktadır. Buradan hareketle, çalışmada yeni uzlaşı iktisadından doğan iktisat politikaları, bu politikalara verilen piyasa tepkileri, etki tepki sürecinden doğan yeni makroiktisadi dinamikler vurgulanacaktır. Uzlaşı kuramı ardından yaşanan tüm bu süreç, uzlaşı yaklaşımının kuramsal, yöntemsel ve politika performansının ölçüsü olarak görülmektedir. Çalışmada ikinci olarak, "New Neo Klasik Sentez Uzlaşı”, o bağlamda sentezlenen, "Yeni Klasik, Yeni Keynesyen” ve "Reel Konjonktür Kuramlarl” arasındaki ilişki tartışılmaktadır. Benzer şekilde, uzlaşı iktisadından doğan iktisat politikaları, politikalara verilen piyasa tepkileri, bu süreçten doğan yeni makroiktisadi dinamikler, uzlaşı yaklaşımının kuramsal, yöntemsel ve politika performansının ölçüsü olarak değerlendirilmektedir. 
Makro uzlaşı sürecinde vurgulanan sentez ${ }^{1}$ kavramı, yerleşik kuramda uzlaşan kuramlara ait varsayımlar setinin, kuramdan üretilen politika önermelerinin bir sentezidir. Reel iktisadi sorunlar karşısında, politika üretmekte yetersiz kalan yerleşik kuram ile kuramın açıklama gücü sınırlı yöntemleri, yeni politikalar ve yöntemlerle kurama eklemlenerek, hızla sentezlenmektedir. Uzlaşı iktisadında sentezlenen kuramlar, çelişen varsayımlar seti ve politika önermeleriyle çalışmalarına karşıllık, yöntemsel uzlaşı gereği birlikte yol almaktadır. Ancak, uzlaşıya verilen piyasa tepkilerden doğan makro dinamikler karşısında, yöntemsel uzlaşıya zorlanan kuramlar özgün ve farklı politika tepkisi üretme avantajlarını kaybetmektedir.

\section{Uzlaşan Kuramlar}

İktisat yazınında uzlaşı tarihi: makroiktisat kuramının tarihi, makroiktisadi düşünce tarihi, makro metodoloji tarihidir. Neoklasik terimi, ilk kez T.Veblen tarafindan "Preconceptions of Economic Science" adlı eserle 1900 yılında kullanılmıştır. Veblen, bu kavramı A. Smith, D. Ricardo ve J. S. Mill gibi klasik iktisatçılar ile L. Walras, S. Jevons ve C. Menger gibi neoklasik, marjinalist iktisatçıları sentezleyen Marshallcı iktisadı eleştiri amacıyla kullanmaktadır. Makroiktisat yazınında ilk uzlaşı, Samuelson'un (1955) "Economics" adlı eserinde "neoklasik sentez iktisat" olarak adlandırılan yaklaşımda gerçekleşmiştir. Neoklasik Sentez Keynezyen Yaklaşım² yerleşik makroiktisadın sert çekirdeğini oluşturmaktadır. Bu yaklaşım, savaş konjonktürüne karşı yükselen yerleşik politik uzlaşının ürünüdür. Ancak, 1970'lerde Keynesyen kuram, Friedman öncülüğünde başlayan ve Lucas'la süren muhalif devrim atağıyla karşı karşıya kalacaktır.

İktisat yazınında tanık olunan ikinci uzlaşı, 1950-1970 döneminde Baumol, Friedman, Jorgenson, Modigliani, Tobin ve Lucas tarafindan, Neoklasik sentez keynesyen iktisada karşı yükselen "karşı devrim" iktisadı, "muhalif uzlaşı” atağıdır. İktisat yazınında tanık olduğumuz son uzlaşı, M. Goodfriend and R. King (1997) tarafından "New Neoklasik Sentez" olarak adlandırılan yaklaşımdır. 1990'larda yükselen modern makro uzlaşı iktisadı, hızla yerleşik yaklaşımda DSGE modelleriyle formalist metodolojinin yeni dili, yeni ifadesi

I Dar anlamda sentez, farklı kuramlar arası tamamlayıcllı̆g vurgu yapmaktadır. Bir anlamda sentezlenen kuramlar arası ilişkilendirilme süreci anlamı taşımamaktadır. Bu açıdan bakıldı̆̆ında, new neoklasik sentez iktisat, yeni keynesyen yaklaşımla reel konjonktür yaklaşımını biraraya getirmiştir.

2 Samuelson (1955), Economics adll eserin üçüncü baskısında "muhteşem neoklasik sentez" olarak adlandırlan kuram, "modern gelirin geçerli belirleyicileri ile klasik ekonominin ilkelerinin bir sentezi" olarak alınmıştır (Samuelson 1955, VI). Samuelson'a göre, Neoklasik sentez yaklaşım karma sistemle yolalan ABD ekonomisinde para ve maliye politikaları yoluyla aşırı genişleme ve yavaşlama sürecini önlemiş, istikrarlı bir ekonomik büyüme firsatı săglamtır. 
haline gelmiştir. Rasyonel bekleyişler yaklaşımının keynesyen sentez ve yeni klasik kuramlar tarafından ekonometrik modellerde kullanılması, yeni uzlaşı sürecini hazırlamış, iktisadın yöntemsel çizgisini fizikten matematiğe çevirmiştir. New neoklasik uzlaşı yerleşik formalist yöntemsel uzlaşı iktisadıdır. Rasyonel Bekleyişler Devrimi, Reel Konjonktür Kuramı (RBC), Yeni Klasik ve Yeni Keynesyen yaklaşımları "modern makro uzlaşı" iktisadına (New Neo Classical Synthesis) yönlendirmiştir.

$\mathrm{Bu}$ gün modern makro uzlaşı yaklaşımının sert çekirdeği, (DSGE) dinamik stokastik genel denge modellerini mümkün kılan rasyonel beklentiler yaklaşımına dayalı varsayımlar setidir. Modern makro uzlaşı sürecinde, iktisat yaklaşımları formalist yöntemsel uzlaşı yoluyla kuramsal bir uzlaşıya zorunlu kalmıştır. Öte yandan, iktisadın ilk makro uzlaşı süreci, Neoklasik sentez yaklaşım, güçlü bir politika uzlaşısı olarak doğan, "yerleşik politika uzlaşısı" dır. Bu konjonktürde yakalanan yöntemsel uzlaşı fırsatı, iktisadı kuramsal bir uzlaşıya zorunlu bırakmıştır. Gerek Neo klasik sentez keynesyen uzlaşı, gerekse neo klasik keynesyen muhalif uzlaşılar, konjonktür karşısında, yerleşik politik uzlaşı olarak yükselirken, yerleşik iktisadı kuramsal bir uzlaşıyla karşıkarşıya bırakmıştır. 1929 bunalımının neden olduğu konjonktürde, J.M. Keynes'in kuramı kapitalist sistem için hızlı büyüme hedefinin kuramsal dayanağı haline gelirken, İkinci Dünya Savaşı'nın ardından, sentez keynesyen uzlaşı iktisadı Soğuk Savaş Dönemi kapitalist dünyada hızlı büyüme hedefinin kuramsal dayanağı haline gelmiştir. Çağdaş modern makro uzlaşı, Soğuk Savaş Sonrası kapitalist dünyanın küresel büyüme kalkınma stratejilerinin sembolü olmuştur.

Öte yandan, muhalif uzlaşılar yerleşik keynesyen politikaların neden olduğu enflasyonist ve stagflasyonist süreç karşısında politika uzlaşısı olarak doğmuş, iktisadı öncelikle kuramsal bir uzlaşıya, ardından matematikden beslenen "yerleşik formalist uzlaşıya" yönlendirmiştir. İktisat bilimi muhalif kuramlar, politikalar ve metodolojilerle neoklasik çatıda bir uzlaşı gündemi yaratmıştır. Tüm uzlaşı sürecini kenetleyen ana gövde, her durumda Neoklasik ve Keynesyen eklentilerle sağlanan uzun dönem denge dinamiklerinden oluşmaktadır. 1950'li yıllarda muhalif uzlaşı iktisadı sistemin yarattı̆̆ enflasyonist kalkınma performansı karşısında, yeniden neo-klasik esintilerin bir ifadesi haline gelmiştir. De Vroey ve Duarte (2012)'e göre makroiktisat yazını farklı muhalifler arasında farklı zamanlarda alternatif uzlaşılara ${ }^{3}$ tanık olmuştur.

3 De Vroey ve Duarte'e göre (2012) iktisat yazınında uzlaşı kavramı belli bir bilimsel topluluğa ait zihinsel kavrayıştır. 1940 'lardan 1990'ların ortalarına kadar süren yazın, Keynesyen uzlaşı olarak adlandırılır. Buna karşın, iktisat yazını 1980 ve 1990'ların ortalarında, birinci kuşak yeni keynesyenler ile yeni klasik/reel konjonktür yaklaşımlarının rakip kuramları arasında karşıtlı̆̆a tanık olur. 1990'ların ikinci yarısından 


\section{Keynes'den Kopuş: Yerleşik Yöntemsel Formalist Uzlaşı Neoklasik Sentez Keynesyen Uzlaşı}

Samuelson 'neoklasik sentez' kavramıyla, Walrascı dengeye yönelen piyasalarda birbirini izleyen süreçleri sentezleyen bir yaklaşım ön görüsü yapar. Bu sentezin ilk aşaması: fiyatı parametri alan maksimizasyon sorununun çözümüdür. İkincisi aşaması: uzun dönemde fiyatı dengeye uyarlayan ayarlama sürecinin inşasıdır. Kuramsal olarak kısa dönemde maksimizasyon amaçlı iktisadi tercihler öne çıkarken, uzun dönemde piyasada optimal kaynak dağılımını sağlayan ayarlama süreci belirleyici olmaktadır. Bu yolla, kısa dönemler süreklilik kazanarak pürüzsüz, kesintisiz bir sürece, uzun dönem denge koşullarına evrilmektedir. İktisat kuramı piyasa aktörlerinin tekil tercihlerini optimizasyon sürecinde türdeşleştirirken, analitik olarak toplulaştırma sorununun çözüldüğünü kabul etmektedir. Bu amaçla, zaman kesintisiz, türdeş ve matematiksel olarak ifade edilen bir soyutlama içinde analize alınmaktadır. İktisadi davranış türdeş, nesnel ve homojen hale getirilmektedir. Zamanı ve insan davranışlarını türdeşleştirerek, pürüzsüzleştiren yöntemsel yaklaşım açısından, analitik olarak malların, piyasaların ve sistemlerin türdeşliğini sağlanmak zor değildir.

Neoklasik sentez kuramda, başta iktisadi davranış olmak üzere, zamanı ve mekânı türdeş sayan yaklaşım, belirsizlik sorununa da analitik olarak çözüm getirmektedir. Zaman durağanlaştırılarak, her türlü makroiktisadi dengesizlik yerçekim etkisiyle dengeye merkez kurama evrilmektedir. Neoklasik sentez iktisat, Keynes'le yollarını ayrırken, Keynesyen dünyaya kollarını açmaktadır. Keynesyen iktisat, fizik temelli ve neoklasiktir. Keynes artık yoktur. Genel denge iktisadında maksimizasyon çözümlemesi, yer çekimi yasalarına dayandırılmaktadır. Samuelson (1947) "Foundations of Economic Analysis" adlı eserde, neoklasik sentez kavramını kullanmadan dinamik ve statik genel denge iktisadını tartışmaktadır. Kısa dönemde dengeden ayrılan ekonomi, uzun dönemde durağan duruma yönelmektedir. Durağan durumda denge yerçekimi merkezlidir. Keynesyen kısa dönemli dengesizlik yer çekimi etkisiyle merkeze yönelen Walrascı anlayışa eklemlenmiştir.

T. Aspromourgos'da (1986) iktisatta sentez kavramı farklı kuramların tamamlayıcılık süreci olarak alınmaktadır. Bir anlamda, neo klasik sentez ve new neo kasik sentezler arası varsayımsal ve kuramsal çelişkiler göz ardı edilmektedir. Aspromourgos'a göre (1986):

günümüze ikinci kuşak yeni keynesyenler ile yeni klasik/reel konjonktür yaklaşımları DSGE modelleri kapsamında bir uzlaşı zemini sağlar. 
"Marshallcl iktisat neoklasik iktisadın özü olduğuna göre, Marshallcı geleneği izleyen Keynes'i neoklasik iktisatla bağdaştıran yaklaşımın yükselmesinde hiç bir sakınca yoktur".

Dolayısıyla, Aspromourgos'a göre, yeni klasik ve yeni keynesyen kuramda varsayımlar setinin new neoklasik iktisat olarak sentezinde bir sıkıntı yoktur.

P. Howitt (1987: 274), O. Blanchard (1987: 634-5), N. G. Mankiw (2006: 35) ve M. Woodford (1999: 9-19) gibi önde gelen iktisatçılar, neoklasik sentez kuramı, piyasa katılığı/ücret ve fiyat yapışkanlığı varsayımlarına dayanan, kısa dönemli Keynes'ci, ancak uzun dönemde neoklasik mükemmel fiyat uyumlamalarıyla işleyen, temiz piyasa yaklaşımları arasında bir uzlaşı iktisadı olarak görmektedirler. Bir anlamda, Marshallcı marjinalist mikroiktisat ve Walrascı marjinalist genel denge iktisadı uzlaştıılmaktadır. Aslında, Marshallcı kısmi denge temelli J.M. Keynes ile Keynes'in karşı durduğu Walrascı genel denge iktisadı uzlaştırılır. Oysa Keynes, Marshall gibi Walrascı genel denge karşıtı bir marjinalisttir (Orhan, 2014). Neo klasik sentez keynesyen iktisatda, efektif talep yetersizliği ve eksik istihdam öngörsü yapan Keynes'ci yaklaşım ve piyasalararası eşanlı denge öngörüsü yapan Walrascı yaklaşım uyumlaştırılmış, tam istihdam varsayımı yeniden klasik kuramsal ortama kavuşmuştur. Bu yolla, iktisat kuramı "neo" ve "klasik" genlerini korumuştur. Keynes ve Keynes tarafindan "Klasik" olarak adlandırılan, yaklaşım sentezlenmiştir. Keynes'in varsayımlarının dışında bir Keynesyen iktisat, yerleşik iktisat doğmuştur.

Landreth ve Colander (2002)'e göre, 1930'lu yıllarda Marshallcı yaklaşımdan, Walrascı yaklaşıma geçen modeller, yöntemsel bireyci marjinalist temele dayanan, arz ve talep mekanizmalarının işlediği denge modelleridir, rasyonalist modellerdir. 1930'larda Keynesyen iktisat toplam kavramları mikro iktisadi kurumlara ekleyerek, farklı bir makroiktisadi çözümleme yöntemi geliştirniştir. Keynesyen kuram, neoklasik iktisadın mikro temelli denge yaklaşımına karşılık, toplamlararası ilişkileri analizin merkezine almıştır. Keynesyen modeller artık neoklasik modellerden farklılaşmıştır. Samuelson'a göre Keynesyen eksik istihdam dengesi, eksik rekabetçi piyasalarda ve idari fiyatların üst yapısında dalgalanmaktadır. Ancak, neoklasik sentez keynesyen yaklaşımda, kuramın mikro kurumları henüz oluşturulamamıştır. 1960'lı yıllarda makroiktisadı mikroiktisat temellerle bağdaştırma sorunu, kuramsal yönden ciddi bir bilişsel çelişki taşımaktadır. Zira marjinalist kuramın mikro kurumları ve davranış kalıpları reel yaşamın piyasa davranış kalıplarını yeterince temsil etmekten yoksundur. Marjinalist temelli mikroiktisadi davranış kalıplarının piyasa realitesi açısından temsil gücü zayıfken, makroiktisadi davranışla türdeşleştirilme girişimi, yerleşik kuramda metodolojik ve politik yönden farklı sorunları beraberinde getirmiştir. Makroiktisat kuramının yeni bir metodolojiye, kuramsal perspektife ve gerçeği daha iyi kapsayan varsayımlar setine duyduğu ihtiyaç, kaçınılmaz bir durumdur. 
Neo klasik sentez iktisat, neoklasik yapıdan hızla formalist ve eklektik bir ekonomiye doğru evrilmiştir. Neoklasik modeller, finansal alanda fiyatlama modellerine, finansal piyasaların doğasını değiştiren yeni finansal entrümanlara dönüşmüştür. Bu yolla, neoklasik iktisat hızla formalist, eklektik modellerle genişleyen bir kurgu sergilemektedir. Yerleşik makro kuram, mikro ve makroiktisadın neoklasik temelinden koparak, formalist eklektik bir uzlaşıya evrilerek kurumsallaşmaktadır. Yerleşik iktisat eklektik kuramlar setiyle kurumsallaşmaktadır. Keynes'in Marshallcı analiz yöntemi, 1950'li yıllarda mikroiktisadi formalizme dönüşmüştür. Sentez keynezyen iktisat, fizikle, ardından matematikle formalleşerek kurumsallaşmaktadır.

Mankiw (2010)'e göre Keynesyen devrim, John Maynard Keynes'in 1930 ve 1940 'lı y1llarda kabul gören makroiktisadi modellerine verilen addır. Keynesyen kuram, başta monetarist iktisat, yeni klasik ve reel konjonktür kuramı olmak üzere, tüm yerleşik neo klasik kuramı kapsamaktadır. Neoklasik makroiktisat, artık "Keynesyen sentez" ya da 'neoklasik sentez' olarak anılmaktadır. Mankiw (2006)'e göre neoklasik sentez kavramı, Marshallcı kuram dışında, yalnızca Walrascı kuramla anılması gereken bir kavramdır. Neoklasik uzlaşı:

“Adam Smith'in görünmez eli ve Alfred Marshall'in arz/talep yaklaşımı ile Keynes'in toplam talep yetersizliği sorunlarının tartışıldı̆̆ kuramlar arası bir uzlaşılır".

Samuelson, Modigliani ve Tobin tarafindan "Neoklasik-Keynesyen Sentez" olarak adlandırılan yaklaşım, uzun dönemde Smith ve Marshallcı iktisat'la Keynes'i bir araya getirmekle, uzun dönemli görülmez elin istikrarını, Keynes'in kısa dönemli gönülsüz işsizlik analiziyle biraraya getirmiştir.

Neoklasik Sentez uzlaşıda, Keynes'de izlenen Marsallcı kısmi denge yaklaşımı, neoklasik Walrascı genel denge iktisadına monte edilmiştir. Bu yolla, ilk neo klasik sentez uzlaşı: kısa dönemde Marshallc1-Keynesyen, uzun dönemde Wallrascı neo klasik genel denge iktisadı arasında kuramsal bir uzlaşıya dönüşmüştür. Her iki dönemde de Marshallcı metodolojinin izleri canlıdır. Oysa kısa dönemde ücret fiyat yapışkanlığı, uzun dönemde temiz piyasa varsayımları altında işleyen uzlaşı iktisadında, varsayımlar arası tutarsızlık açıktır. Uzlaşı iktisadında kuramsal uzlaşı kuramsal tutarsızlıkla sağlanmıştır (Orhan, 2014). Keynes ve sentez keynesyen iktisat arasındaki kuramsal tutarsızlık sorunu, Mankiw'in Marshall ve neoklasik sentez ayrımı konusunda gösterdiği hassasiyetten daha önemli bir soruna işaret etmektedir. Keynes'in klasiklerden saydığı marjinalist neo klasik iktisada karşı konumu, tam bir muhaliftir. Keynes'in bu muhalif tavrını göz ardı eden sentez keynesyen uzlaşı, yerleşik iktisadı türdeş bir uzlaşı tabanına doğru zorlamaktadır. İnsanı, zamanı türdeşleştiren iktisat yaklaşımı kendini ve kuramını da türdeşleştirmektedir. Yerleşik iktisat, ekonomi politik konjonktür gereği doğan politik uzlaşı görünümü kazanmaktadır Oysa, 
neoklasik sentez keynesyen ${ }^{4}$ uzlaşı, piyasaların kendiliğinden dengeye uyumu dışında kuramsal yakınlık içermemektedir.

Neoklasik sentez keynesyen iktisat adıyla anılan uzlaşı, politika uzlaşısıdır, savaş konjonktürü iktisat bilimini kuramsal bir uzlaşıya zorlamıştır. Neoklasik sentez makro uzlaşı, klasiklerle başlayan, neoklasikler ve Keynes'de süregelen "piyasa" ve "pozitivizm" ideolojisinin, zoraki ürünüdür. Savaşın ardından, piyasalardan ve neoklasik çevrelerden yükselen kalkınma ve büyüme kaygıları karşısında meşruiyet kazanan, politika uzlaşısıdır. Samuelson'da ([1963] 1966: 1543) tesis edilen neo klasik sentez iktisat, marjinalist mikro analizin Neoklasik Keynesyenler tarafindan sahiplenilmesiyle doğan kuramsal bir sentezdir. Hicks tarafindan 1940 yılında yazılan "Value and Capital" (1939) ve 1947 yılında Samuelson tarafindan yazılan "Foundations" adlı eserler, marjinalist kuramin tüm unsurlarını bir araya getiren son çalışmalar olmuştur. Savaş Sonrası neoklasik sentez kuram, farklı kuramsal mantık ve kurgu içinde, farklı araçlar yoluyla yeni bir sürece evrilmiştir. Neoklasik kuram rekabetçi ekonomide Arrow-Debreu genel denge modelleriyle, genel dengede istikrarın açıklanmasını hedeflemiştir. Neoklasik kuramın kıtlığa dayalı modelleri, iş dünyasında değişen karar verme süreçlerine uygulanmaya çalışılmıştır.

Samuelson'un ekonomiyi dengesizlikten dengeye yönlendiren analizde eksik bıraktığı 'tâtonnement' süreci, D.Patinkin (1956) tarafindan "Money, Interest and Prices" adlı gündeme gelmiştir. Patinkin, Walrasyan kavramlarla Keynesyen gönüllü işsizlik kavramını tartışmaktadır. Lucas ([1980] 1981: 278)'a göre, Patinkin tarafindan yapılan analiz "neoklasik sentez", kavramının en etkili kullanılış şekli olmuştur. Patinkin'de gönülsüz, işsizlik bir dengesizlik durumudur. Ayarlama sürecinde dengeye yönelim yavaş seyretmektedir. Mal yerine, bono talebinin arttı̆̆1 piyasalarda, makroiktisadi dengeler bozularak, istihdam sorununa neden olmaktadır. Walrascı tâtonnement süreciyle mal piyasalarında hızla ayarlanan fiyatlar, neo klasik keynesyen dünyada artık gecikmeli olarak ayarlanmaktadir.

Gecikmeli ayarlanan fiyatlar mal piyasalarında toplam talebi düşürerek, arz fazlası yaratmakta, firmalar üretimi, stokları ve emek talebini azaltmaktadır. Bu yolla, neoklasik sentez iktisat, efektif talep yetersizliği ve gönülsüz işsizlik sorununu açıklama şansı kazanmaktadır. Ancak, ekonomide gönülsüz işsizlik sürekli bir durumdur. Bu bir denge durumu değildir, mal fiyatlarının düşmesiyle başlayan geçici bir durumdur. Patinkin'e

4 Ücret esnekliğinin düşük oması nedeniyle kusa dönemli dalgalanmaları tartışan Keynesyen kuram ile uzun dönemde ayarlama sorunlarının göz ardı eden genel denge kuramını içeren görüş 'neoklasik sentez'yaklaşımdır (Howitt, 1987: 274). 
göre, işsizliğin nedeni, fiyat yapışkanlığı sorunu değildir, fiyatların gecikmeli ayarlama sürecidir. Gecikmeli ayarlama yoluyla ekonomi Walrascı dengeye yönelmektedir. Keynesyen gönülsüz işsizlik yerçekimi gücüyle, Walrascı dengeye yönelmektedir. Colander ve Landreth (2002)'e göre, Patinkin'de vurgulanan gecikmeli ayarlanan fiyatlar, Walrasc1/Keynesyen tutarsızlığı hedef alan eleştirilere cevaben, yerleşik iktisada daha güçlü bir perspektif kazandırmıştır.

\section{Keynesyen Karşı Devrim: Muhalif Uzlaşı}

Karşı devrim süreci, Baumol, Friedman, Jorgenson, Modigliani ve Tobin gibi iktisatçılar tarafindan, 1950-1970 döneminde talep yönlü neo klasik sentez keynesyen iktisada karşı, mikroiktisadi kurumlar ve "Doğal Oran Hipotezi" bağlamında yükselen muhalif atağın ürünüdür. Neo klasik sentez yaklaşım karşısında karşı devrim süreci, özellikle finansal piyasaların etkinliği tartışmasına dayanır. 1970 petrol krizinin ardından, enflasyon ve işsizlik birlikteliğine karşısın "doğal oran" yaklaşımı, küresel ekonomi politikaları olarak yerleşik iktisada damgasını vurur. Yerleşik makroiktisat yazını, artık monetarist eklentili sentez keynesyen kuramdır, süper rasyonaliteyle yüklü temsili ajanlarla maksimizasyon davranışı içinde, mikroiktisat temelli bir içerik kazanır. Rasyonel bireylerin maksimizasyon davranışıyla işleyen, mal, iş gücü ve para piyasalarında etkinlik koşulunda yeni bir iktisat yükselir (Friedman, 1968).

Talep yönlü Keynesyen kuram, karşı devrimci yaklaşımında rasyonelite temelli mikroiktisadi kurumlar tarafından genişletilmiştir. Friedman ve Modigliani tarafindan cari gelirden sürekli gelire geçilerek, finansal varlıklar, konut piyasaları ve servet gibi değişkenler tüketim ve para talebi fonksiyonuna eklenmektedir. 1950'li ylllarda monetarist iktisatla yükselen makro ekonometrik modellerde, öncelikle neo klasik sentez keynesyen kuramın makroiktisadi formal temelleri, 1960-1970'li y1llarda ise, mikro kurumları inşa edilerek, makroiktisat yeniden mikroiktisada bağlanmıştır. 1980'li yıllarda yerleşik makro kuramda cari gelir ve cari tüketim ilişkisi; cari tüketimde servet etkisi; cari gelir ve reel çıktıya bağlı hızlandıran etkisi gibi tüketim fonksiyonuna dayanan toplam talep dinamikleri göz ardı edilmiştir. 1970'lerin ortalarında ekonominin arz yönünü içeren kuram yükselmiştir. Petrol gibi esnek fiyatlı mallar ile yapışkan fiyatlı malları birlikte tartışan yeni yaklaşım yoluyla, arz şoklarını neoklasik yaklaşıma ekleme olanağı doğmuştur. Lucas ve Sargent'in katkılarıyla, Keynesyen iktisat itibar kaybetmiştir.

Petrol ve gıda gibi mallarda ve döviz gibi emtiyalarda fiyat artışı, ekonomide emtiya balonu yaratmıştır. Ancak, fiyat şoku dışında kalan ürünlerde talep artışı, enflasyonist süreci tetiklemiştir. Dezenflasyon karşısında, ücret yapışkanlığıyla fiyat şoku dışında kalan reel talebin azalış trendi, ekonomileri resesyon ikilemiyle karşı karşıya bırakmıştır. Piyasalarda fiyat istikrarı koşulu bir yandan reel GDP'ye istikrar kazandırırken, bir yandan da resesyon riskini artırmıştır. 1970'lerin ekonomi politik konjonktürü 
karşısında, keynesyen kuramın enflasyon öngörüsünde başarısız oluşu, iktisat yazınında ikinci uzlaşı sürecini hazırlamıştır. Yeni klasik iktisat keynesyen kuramı makro toplamlar kuramından mikro kurumsal varsayımlara taşıyarak, yeniden neoklasik varsayımlara yaklaştırmıştır. Bu yolla, yerleşik sentez keynesyen temelli makroiktisat kuramı yeni klasik varsayımların hâkimiyetine girmektedir. Yerleşik sentez keynesyen kuramda makroiktisadi kurumları sağlamlaştırma çabaları, 1980’li yıllarda yeni klasik iktisata karşı yeni keynesyen iktisadın yükselişine neden olmuştur.

1980'li yıllarda Sargent ve Lucas'ın neoklasik Keynesyen paradigmaya karşı retoriği, Keynesyen kavramını gözden düşürmüştür. Keynesyen ekonomiler birinci kuşak negatif eğimli Phillips eğrisinin amprik başarısızlığı karşısında zayıflamıştır. Gordon (2009)'a göre, 1970 öncesi Birinci Kuşak Phillips analiziyle Keynesyen ekonomi arasında mantıksal bir ilişki yoktur. Bu teori fiyat rijiditesiyle işleyen toplam talep kuramıdır. Sürekli negatif Phillips almaşığı, bekleyişleri, doğal oran hipotezini ve arz şoklarını gözardı eden bir sistematikle işlemektedir. Keynesyen kuramın temiz olmayan piyasalarda dengesizlik karşısında başarısız olma nedeni, sabit fiyatlarla işleyen toplam talep modelinin enflasyonist süreçte toplam arzı göz ardı etmiş olmasıdır.

1970 petrol krizini izleyen stagflasyonist süreç karşısında, yeni klasik ve reel konjonktür kuramları tarafından yapılan arz analizi, yerleşik iktisada damgasını vurmuştur. Yeni klasik ve reel konjonktür kuramları yerleşik makro iktisadın yeni uzlaşı zeminini hazırlamıştır. Ancak, bu durum kısa dönemli Keynesyen toplam dinamiklerin kullanıldığ yapısal modellerin terk edildiği anlamına gelmemektedir. Yerleşik sentez keynesyen yaklaşım, dinamik genel denge modelleriyle kısa ve uzun dönemli ekonomik sorunların, uyuşmazlıkların, daha gerçekçi temsillerle analizini hedeflemektedir. $\mathrm{Bu}$ modellerin yükselişiyle, savaş sonrası yükselen sentez keynesyen makro ekonometrik modeller çökmüştür. Yeni klasik modellerin önemli bir kısmı neoklasik temelli büyüme modelleridir. Bu gelişmeler karşısında R.E. Lucas ve T.J. Sargent (1978: 69), sağlam bir kuramsal ve ekonometrik temelden yoksun sayılan keynesyen makro ekonometrik modelleri revize etmek yerine, yeterince olgunlaşmamış, modelleri yerleşik yazına taşımıştır.

1980’li yıllarda modern ekonomiler artık keynesyen ekonomilerin parçası değildir. Sentez keynesyen mikro modellerin küresel rasyonalite, mükemmel rekabet öngörüsü yapması olanaksızdır. Oyunlar kuramıyla gelişen matematiksel modeller yerleşik iktisatta belirleyici konuma gelmiştir. İktisat fizik ya da mekaniğin metaforlarına bağlanmak zorunda kalmadan, ön görü yapabilen modellerle çalışma firsatı yakalamıştır. Matematiksel modelerin hâkimiyetine rağmen, Friedman'ın pozitivist metodolojisi ağırlığını korumaktadır. Zira iktisat kuramının performansını, varsayımların yanlışlanabilirliğine (test edilebilirliğine) bağlayan, ön görü gücünü analizin merkezine alan yaklaşım, yerleşik iktisadı formalist yönteme zorunlu hale getirmiştir (Hodgson, 2012). Friedman'ın Popperyan yorumu, yerleşik iktisatta önemli bir kırılma noktası olmuştur. Artık iktisat öngörüyü hedefleyen rasyonel davranış kuramlarına hazır bir haldedir. 


\section{Yerleşik Neo Klasik Sentezde Yeni Klasik ve Yeni Keynezyen Paradigma}

Keynesyen iktisat Clower'ın (1965) fiyat yapışkanlığı ve Patinkin'in (1956) emek piyasası analiziyle ivme kazanır. Benassy (1976) ve Leijonhufvud (1968)'un katkılarıyla Barro ve Grossman'ın emek ve mal piyasalarını bir araya getiren genel denge modelleri birleşerek neoklasik keynesyen iktisada farklı bir yön verir (Gordon, 2009). Yapışkan fiyatlarla işleyen Keynesyen IS-LM modelleri karşısında, Barro ve Grossman tarafından geliştirilen sabit fiyatlı toplam talebi çıktıya hızla aktaran modeller öne çıkarılır. Toplam talepde ve çıktıda daralma süreci emek piyasalarında çalışma saatlerinin ve üretim miktarının düşmesiyle açıklanır. Patinkin'de, Marshallcı nominal talep ve emek talebi ayrımı vurgulanarak, resesyon karşısında işgücünün, ücret ve fiyat değişimine çalışmak ya da boş zaman tercihiyle esnek kalamayacağı vurgulanır. Benzer şekilde, resesyon karşısında ekonominin arz yönünde firmaların satış esnekliğinin azalışı, temiz piyasa modellerinin başarısızlığı öne çıkarılır.

1975-1978 döneminde arz şoklarını ekonomiye ekleyen modeller hızla analizlere dâhil edilir. Dornbush'da fiyatlar ve işsizlik ya da çıktı açığı alınarak, beklenen Phillips Eğrisi (PC) ve arz şoklarının değiştirdiği Phillips eğrisi, enflasyon ve çıktı değişimine göre bozulan nominal GDP dengesi, makroiktisat yazınına girer. Bu yolla, dinamik toplam arz ve dinamik toplam talep modellerinin basit eşitlikleri ortaya çıkarılır. Sürekli aşağı yukarı hareket eden nominal GDP oranı, sürekli yükselen enflasyon düzeyi, beklenen ve gerçekleşen enflasyon farkına göre değişen uzun dönem sıfır işsizlik değeri ya da çıktı açı̆̆ yerleşik iktisat kuramının gündemine girer (Gordon, 2009).

Friedman-Phelp-Lucas tarafından geliştirilen esnek fiyatlarla işleyen, piyasayı temizleyen yeni klasik modeller konjonktür sorunuyla ilgilenmemiştir. Fischer (1977) ve Taylor'un (1980) katkılarıyla reel/nominal ücret/fiyat yapışkanlığı ve enflasyonist atalet mekanizmasının tartışıldığı modeller ile rasyonel bekleyişlerin birleştirildiği modeller, yerleşik makro uzlaşı iktisadının yeni gövdesini oluşturmaktadır. Yeni Keynesyen iktisatta kuramsallaşan bu modeller, sistematik para politikalarının reel etkilerinin tartışıldığı Fisher eşitliği (1977) ve dinamik enflasyon modellerinin tartışıldığı Taylor (1980) kuralı olarak geliştirilir. Cooper John'da (1988) koordinasyon başarısızlığı sorunu; Okun'da makro dışsallık sorunu; Gordon ve Phelp'de arz şokları; Akerlof-Yelen (1985) ve Mankiw (1985)'de menü maliyetleri sorunu yeni keynesyen analize eklenir. Ball ve Romer (1991)'in "Koordinasyon Başarısızlığ olarak Yapışkan Piyasalar" makalesinin ardından "Temiz Olmayan Piyasalar" (non-market clearing) olarak anılan yeni keynesyen makro yazın, yerleşik makro iktisadın en güçlü kanadını oluşturmuştur. 1970 petrol krizini izleyen stagflasyonist realite karşısında, yeni keynesyen kuramın toplam talep dinamikleri yerleşik iktisatda hâkim hale gelir. Yeni Klasik iktisadın yükselişi karşısında, Keynesyen iktisat temiz olmayan piyasalarda işleyen birinci kuşak Phillips analizinden koparken, petrol gibi esnek fiyatlı emtia piyasaları ile arz şoklarının kurama eklenmesi başarılmıştır. 
Yeni klasik etkiyle rasyonel bekleyişler koşulunda, negatif ve pozitif yönlü enflasyon işsizlik ilişkilerinin tartışıldığı dinamik toplam arz ve dinamik toplam talep modelleri geliştirilir. Bu yolla, modern makroiktisat kuramı keynesyen kavramlardan uzaklaşır (Gordon, 2009). Yeni keynesyen ücret ve fiyat yapışkanlığı modelleri, kuramsal olarak Clower-Patinkin-Barro-Grossman'ın genel denge modellerini tamamlar. 1978 dönemi makroekonomi, yeni keynesyen kuramla yeni bir bakış açısı kazanmaktadır. Yerleşik makroiktisat yazını dinamik toplam arz ve dinamik toplam talep modelleriyle yükselmektedir. Bu modeller enflasyon ve işsizlik arasındaki ilişkinin nedenlerini açıklarken, finansal ve reel ekonomi arasındaki bağlantıların anlaşılması ve test edilmesinde önem kazanır. 1978 dönemi makroiktisat yazınında enflasyon ve işsizlik ilişkisinin yönü, fiyat ve miktar ilişkisinde olduğu gibi, arz ve talep şoklarının büyüklüğüne bağlanır. Büyük uzlaş1 (Great Moderation) sürecinde ise, büyüme kuramı yoluyla makro kuram kısmi ücret ve fiyatların yapkanlığı analizden uzaklaşarak, işsizlik modellerinden kopar. DSGE modellerinde (a general dynamic stochastic general equilibrium model) modern üretim fonksiyonunda faktör girdilerinin optimal kullanımıyla, potansiyel fiili GDP açığı gibi amprik gelişmeler tahmin edilmeye çalışılır.

1960'lı yıllarda faiz ve beklenen gelecek tüketimle açıklanan keynesyen talep yanlı iktisat, 1980'li yıllarda, yeni klasik ve monetarist etkilerle sürekli gelir ve serveti tüketim kuramına ekleyen DSGE modelleriyle tanışmıştır. Yerleşik iktisat yazını, Clower, (1965), Campbell ve Mankiw (1990) gibi isimlerin kuramsal ve amprik katkılarıyla, parasal sıkılaştırmayla başlayan cari gelir ve servet değişiminin tüketim harcamalarına etkilerini modellenmektedir. DSGE modelleri yeni klasik iktisadın temiz piyasa varsayımlarına dayanan modellerle, yeni keynesyen iktisadın fiyat yapışkanlığı varsayımlarını kombine eden modellerin uzlaşı zemini haline gelmiştir. DSGE modelleri Blanchard ve Galí (2007) tarafından "ilahi tesadüf" olarak adlandırılan, yeni keynesyen modellerden çıkarılan bir durumdur. Neo klasik sentez keynesyen yaklaşımın konjonktür kuramı tarafından kullanılan DSGE modelleri, toplam arzın pürüzsüz bir trend içinde ilerlediği, toplam talebin makroiktisadi değişkenlere oldukça yumuşak etkiler taşığı varsayımlarıyla çalışır.

Diğer yandan, Kydland ve Prescoot tarafindan Büyük Depresyon gibi krizleri arz şokları kapsamında açıklayan "Reel Konjonktür Modelleri” yerleşik makro kuramın yönünü keynezyen yazından uzaklaştırmayı başarır. 1970'li yılların sonunda yerleşik makro kuram, keynezyen talep yanlı Phillips Analizinden (PC analizi) uzaklaşırken, arz şokları dışsal değişken olarak alınır. 1978 sonrası konjonktür kuramına dayalı modern makro kuram, Yeni Açık Makroiktisat (New Open Macro Economics), "Dinamik Stokastik Genel Denge Modelleri” (DSGM) olarak anılır (Woodford; 2009). New neo klasik sentez yaklaşımda, Smets ve Wouters $(2003,2007)$ tarafindan kullanılan amprik DSGE modellerinde denge tamamen pürüzsüz trend içinde, doğal çıktı düzeyinden uzaklaşmaktadır. Artık, konjonktürel dalgalanmaların tek nedeni parasal sorunlar değildir. Yapışkan ücret, fiyat ve eksik bilgiyle çalışan DSGE modelleri, sistematik para politikalarının olumsuz reel etkilerini analize dâhil eder. Bir anlamda, para politikalarının konjonktürel etkilerinin modellenmesi 
hedeflenir. Uygun para politikası setiyle makroiktisadi istikrar hedeflenir. Para politikaları ekonomik istikrarın temel belirleyicisi haline getirilir. Amprik DSGE modellerinde Taylor ve diğerleri tarafindan tartışılan konjonktür dalgaları analiz eklenir. Enflasyonun kontrolünde işleyen para politikaları etkindir. 1980-1990 dönemi enflasyon karşıtı politikalarda merkez bankaları enflasyon kontrolünde başarılı olmuştur.

Savaş Sonrası makroiktisat yazınında yükselen para politikalarının kapasite kullanımı ve arz maliyetleri gibi reel iktisadi faaliyet üzerindeki etkileri, fiyatlar genel düzeyi üzerinde etkileri belirleyici değildir. Ancak, DSGE modellerinde PC etkileri varlığını sürdürmektedir (Woodford 2009). 1980'li yıllarda başlayan uzlaşı dalgası, yeni keynesyen, yeni klasik ve reel konjonktür kuramı tarafindan kullanılan DSGE modelleri üzerinde sağlanan bir uzlaşıdır. Matematiksel formalistik metodolojiyle üretilen DSGE modelleri, reel konjonktür kuramı, yeni klasik kuramı ve yeni keynesyen kuramı, makro kuramsal uzlaşıya zorlar.

\section{Yerleşik Modern Makro Uzlaşı: Makro Kuramsal Uzlaşı}

1980'lerin başında yeni klasik ve yeni keynesyen kuramlar oldukça sert çatışma ortamı içinde yol almıştır (Goodfriend, 2006). Samuelson tarafından Keynes sonrası makroiktisat ayrımında kullanılan neoklasik sentez kavramı, Goodfriend $(2004,2007)$ ve King (1997, 2004) tarafından yeni makro uzlaşı yaklaşımının açıklanmasnda "Yeni Neoklasik Sentez" (New Neo Classical Syntehesis) olarak güncellenmiştir. Goodfriend ve King (1997)'e göre:

"New neoklasik sentez yaklaşım eski sentez iktisadın ruhunu miras aldığı için, new neoklasik sentez olarak adlandirllir. New neoklasik sentez kuram oldukça geniş kapsam olan, yerleşik iktisat akımlarının uzlaşısıldır. Makroiktisadın entelektüel alanda süren dağınık ve karmaşı görüntüsü ile metodolojik farklllıklar, son on yllda farklı yorumlarla makro kuramı Yeni neoklasik sentez uzlaşıya yönlendirmiştir".

Goodfriend ve King (1997)'in eski sentez iktisadın ruhu saydığı, neoklasik sentez iktisatla benzerlik gösteren new neoklasik sentez iktisadın kavramsal içeriği, en az Samuelson'un neo klasik sentez iktisat kavramı kadar karmaşık ve sorunludur. Neoklasik ve Keynes sentezinin taşıdı̆̆ içerik sorunu, Goodfriend ve King (1997) tarafından tercih edilen kavramında devam etmektedir. Neo klasik sentez iktisat ve new neoklasik sentez iktisat kuramı ne birbirlerinin takipçisi nede bir üst modelidir. Gerek kavramsal açısından, gerekse kuramsal ve metodololojik açıdan süreklilik ilişkisi yoktur. Ancak, her iki makro uzlaşı yaklaşımının ortak noktası, her koşulda piyasa söylemine yaslanan, yöntemsel poztivizt metodolojinin sağladığı uzun dönem denge yaklaşımıdır. 
Yeni uzlaşı iktisadı, Meyer (2001) ve Arestis (2007) tarafından "Yeni Makroiktisadi Konsensus", Blanchard (2008) tarafindan "Yerleşik Ekonomide Genel Konsensus", Woodford (2009) tarafindan "Yeni Konsensus" olarak adlandırılmıştır. Gordon (2009)'a göre makro uzlaşı nitelemesi, 1947-1984 dönemi makroiktisadi oynaklığa karşılık, 1984-2007 dönemi koşullarının "Büyük İtidal” (Great Moderation) dönemi olarak algılanmasından kaynaklanmaktadır. Goodfriend ve King (1997) tarafindan yeni neoklasik sentez olarak adlandırılan sürecin "yerleşik makro uzlaşı” içerikli kavramla adlandırılması daha uygundur. Neoklasik sentez keynesyen kuram ve birinci kuşak yeni keynesyen kuramda makroiktisadi analiz, kısa ve uzun dönemlerden oluşan bir süreç içinde dengeye yönelmektedir. Piyasayı temizleyen modeller birbirini izlemektedir. Godfriend ve King'in "yeni makroiktisat araştırma programını, eski sentez iktisadın ruhu" sayan fikrin aksine, DSGE modellerini kullanan yeni sentez yaklaşım, neoklasik sentez ruhtan oldukça uzaktır. Lucas'ın homojen makro araştırma programı daha baskındır.

Gerçekte, modern makro uzlaşı kavramının neoklasizm bağlamında olup olmadığının sorgusu oldukça önemlidir. Neoklasik paradigma belli bir düşünceyi, yaklaşımı temsil etmektedir. Neoklasik iktisatta marjinalist analiz setinin içerdiği marjinal verimlilik kavramı, tüm kuramların ortak paydasıdır. Neoklasik yaklaşım, marjinalisttir, ekonominin kendiliğinden tam istihdam genel dengesini hedefleyen neoklasik ilkeler bütünüdür. Küresel rasyonalite varsayımına dayanır. Neoklasizm: Walrascı uzun dönemli genel denge yaklaşımı; Marshallıı kısa dönemli arz/talep analizi ve zamansız işleyen laissez faire ideolojisini yaşatır. Oysa modern makro uzlaşı kuramı, neoklasik yaklaşıma göre daha eklektik, daha kapsamlı ve küreseldir. Her iki yaklaşımda yerleşiktir, ancak her iki yaklaşımda neoklasik değildir (Colander \& Landreth, 2002).

Neoklasik sentez: Walrascı neo klasik iktisat ve Keynesyen iktisadın sentezidir. Kuramlar ana eğilimlerini terk ederek neoklasik sentezde uzlaştırılır. Neo klasik sentezin Walras dışı denge olasılığı zayıftır. Aksine, modern makro uzlaşı yaklaşımı, new neoklasik sentez yaklaşım, reel konjonktür kuramı ve birinci kuşak yeni keynesyen iktisadın bir kombinasyonudur. Mükemmel rekabet, esnek fiyat ve dikatomi varsayımlarına dayanan reel konjonktür yaklaşımı ile eksik rekabet, ücretf/iyat yapışkanlığı ve yansız olmayan para varsayımlarına dayanan yeni keynesyen yaklaşım arasında yöntemsel farklılıklara ragmen, kabul edilen yöntemsel uzlaşıyla işler. Modern makro uzlaşı yaklaşımında gönülsüz işsizlik önemli bir sorundur. Neoklasik sentez uzlaşıda terminolojiye uygun tek bir model kullanılır. Modern makro uzlaşıda DSGE modelleri her iki ekolün kendi terminolojisiyle kendi varlığını sürdürdüğü kuramsal, yöntemsel ve politika sentezleridir.

Neoklasik sentez iktisadın gövdesini oluşturan keynesyen yaklaşımlar kendi içinde farklılaşmaktadır. Yeni keynesyen ve reel konjonktür kuramını kapsayan new neoklasik sentez iktisat ile Walrasci/Keynesyen sentezi kapsayan neokasik sentez iktisat arasındaki süreklilik ilişkisi zayıftır. Diğer yandan, Walrasc1/Keynesyen sentez yaklaşım, Patinkin tarzı sentez keynezyen yaklaşım ve Walrascı/Yeni Keynesyen sentez yaklaşımlar 
arasındaki süreklilik bağı da zayıftır. Neoklasik sentez keynesyen ve birinci kuşak yeni keynesyen iktisat, kısa ve uzun dönemli iki üst süreci kapsayan makroiktisadi analiz yöntemiyle çalışırken, DSGE modelleri, kısa ve uzun dönem kavramları yerine, durağan durumda denge kavramını kullanmaktadır.

Ancak, Neo klasik ekonomi tek tip modellerle çalışmaktadır. J. Scuhumpeter'a göre, modern modeller neoklasik modellere göre, çoklu denge modelleridir, dinamik modellerdir ve denge yoktur. Modern ekonomi modelleri içsel tutarlılık gösteren varsayımlarla işlemektedir. Neoklasik modeller: küresel rasyonalite ve bireysel fayda maksimizasyonu gibi iki kritik ön kabulden hareket etmektedir. Ancak, yeni yerleşik uzlaşıda, evrimci oyun modelleri grup için maksimizasyonu bireysel makzimizasyona tercih etmektedir. Bilişsel çelişkiler (cognitif dissonance) ya da ajan temelli simülasyonlar kurama eklenir. Bu mikro kurumsal çerçeve, neoklasik modellerden oldukça farklıdır. Modern makroiktisatta sınırlı rasyonalite modelleri, mikroiktisatta alturistik modeller öne çıkarılmaktadır.

Chari ve Kehoe (2006)'e göre, “modern makroiktisat” kuramının temel ilkeleri iktisatçıların fildişi kulelerinde üretilen varsayımlar setine dayandırılmamıştır. Son otuz yılda makroiktisat kuramı ve uygulamaları önemli gelişmeler kaydetmiştir. Modern makro uzlaşı yaklaşımı, başta ABD olmak üzere, diğer ülkelerde kuram ve politika değişimlerinin yansımalarını kapsamaktadır. Mankiw'e göre (2006) yeni neo klasik sentez yaklaşım, yeni klasik ve yeni keynesyen iktisat gibi modern makroiktisat okullarının birleşimidir. New neklasik sentez yaklaşım, kısa dönemli konjonktürel dalgaların bir uzlaşısıdır. New neoklasik sentez makro iktisat, çağdaş yerleşik makroiktisadın kuramsal ifadesidir. Lucas'ın Reel Konjonktür İktisadı (RBC) ve birinci kuşak yeni keynesyen iktisat arasında süren çatışmayı new neoklasik sentez yaklaşımda uzlaşıya çeviren, DSGE modellerinin formalist gücüdür. Blanchard (2009)'a göre DSGE uzlaşısı, rakip vizyonlar arasında çatışmanın ardından doğan harmonik bir durumdur. 1970'li yıllarda keynesyen kavram üzerinde süren çatışma, kuramcıları farklı yöntemlerle gerçeklere ulaşma konusunda uzlaşıya zorunlu bırakmıştır. Yeni klasik, yeni keynesyen ve konjonktür yaklaşımı modelleme yöntemi konusunda uzlaşmıştır.

Yerleşik makro uzlaşı iktisadı, RBC ve yeni keynesyen kuramı birleştirmektedir. Yerleşik uzlaşı iktisadında fiili ve optimal çıktı düzeyi arasında çıktı açıkları azaltılarak ekonomi dengeye taşınır. Etkin çıktı düzeyi, şoklar karşısında aşağı yukarı yönde salınan, sürekli büyümeyen potansiyel çıktı düzeyidir. Bu durum, enflasyonun kontrolünde para politikaları üzerinden Merkez Bankalarına politika firsatı sunar. Modern makro uzlaşı iktisadında para politikalarının tercihi monetarist bir kazanım olsada, Phillips Eğrisinin güncel bir versiyonudur. Yerleşik makro uzlaşı iktisadı, DSGE modelleri yoluyla RBC kuramının metodolojik avantajlarından beslenmekle birlikte, kısa ve uzun dönem analizlerinde ücret ve fiyat yapışkanlığ 1 gibi yeni keynesyen varsayımlara yaslanmaktadır. 
Yerleşik iktisat, new neoklasik sentezde, Marshallcı yöntemin dışında modern ekonominin modellerini üretmektedir. Modern ekonominin temel ajandası pragmatizmdir. $\mathrm{Bu}$ modellerde, uzlaşı kuramından ekonominin tamamını kapsayan bütüncül analizler beklenmemektedir. DSGE modelleri belli sorunlara çözüm üreten analizleri hedeflemektedir. Landreth ve Colander (2002)'a göre, modern mikroiktisadın bilinmesi popüler modelleri kullanmak anlamına gelmektedir. Modern iktisat marjinalist analizin ötesinde, amprik olarak test edilebilir teknik araçların kullanıldığı matematiksel modellemelere dayandırılmaktadır. Formal matematiksel modeller sezgisel modellerden (heuristik) daha katı ve daha kesin sonuçlar vermektedir. Modern makro uzlaşı iktisadı, Marshallcı yöntemi izleyen neoklasik modellerde olduğu gibi söylem ve içerik analiziyle işlememektedir. Modern makro uzlaşı matematiksel tekniklere dayalı eklektik bir metodolojinin ürünüdür.

Zaman zaman makro uzlaşı modelleri Krugman gibi yeni keynesyen çevrelerden ciddi eleştiriler almakla birlikte, bu eleştirilere maruz kalan iktisatçılar çoğunlukla bilimsel olmamakla, etkin piyasalar hipotezini iyi anlayamamakla, "tatlı su iktisatçısı" olmakla itham edilmiştir (Krugman, 2009). Krugman'a göre "İyimser bir yaklaşımla makroiktisat son otuz yıldır yararsızdır, kötümser yaklaşımla zararlı olmuştur”. Krugman ve Buiter (2009)'a göre son otuz yıldır toplulaştırılmış iktisadi davranış ve politikalarla ilgili anlayış konusunda Anglo-Amerikan üniversitelerinde süren eğitime ayrılan zaman ve kaynakların özel ve sosyal maliyetleri çok yüksektir.2008 resesyonu, iktisadi yaşamda piyasaların, iktisadi kurumların; iktisadi kurumları analiz dışı bırakan kuramların; formalist analiz dışında kalan iktisadı ve kuramcıları göz ardı eden yerleşik kuramın krizidir. 2008 resesyonu iktisadi analizi modelleyemeyen, kuramı yalnızca ön görüye indirgeyen yerleşik iktisadın, makro uzlaşı iktisadının krizidir. 2008 resesyonu, iktisat kuramcılarına öncelikle kendi krizlerini, ardından iktisat biliminin ve yerleşik iktisat kuramının krizini görme firsatı tanımaktadır. 2008 resesyonu karşısında yerleşik makro uzlaşı kuramında DSGE modelleri ve politika önermeleri reel ve finansal sorunlar karşısında sınanma şansı kazanmıştır. 2008 Resesyonu DSGE modellerinde yer alan varsayımlar arası tutarsızlığın, iktisat kuramının performansını zayıflatan etkilerin anlaşılmasında önemli bir firsattır.

Colander iktisat kuramının parçalı duruşu konusunda kaygı duymakta haklıdır. Çağdaş yerleşik iktisat, uygulamalı iktisat dışında kalan iktisat çevrelerinin çözümleyemeceği kadar formalist ve matematikseldir. Hatta benzer modellemeleri ve yöntemleri kullanmayan uygulamalı iktisatçılar arasında farklı modellerin tercihi söz konusu değildir. Zaman zaman farklı modellerden ulaşılan sonuçlar, uygulamalı iktisat çevrelerinde bir bütün olarak çözümlenememektedir. Uygulamalı iktisat yazınında üretilen kuramsal bilginin iktisat yazınında yer alması, iyimser yaklaşımla zamana kalmakta, kötümser yaklaşımla gözardı edilmektedir. Benzer sorun yerleşik iktisat dışında kalan heterodoks dünya için geçerlidir. Heterodoks kuramcılar tarafından iktisat kuramları, yaklaşımları ve dinamikleri tartış1ırken, izlenilen kavramsal terminoloji, kulanılan söylem, dil yerleşik iktisatta bir karşılık, anlam bulamamaktadır. Yerleşik iktisatta, formalist yöntem ya da 
problematik dışında kalan bağlam, anlam ve dil ötekidir. Uygulamalı iktisatçılar tarafindan kullanılan modelleme teknikleri ve matematiksel yöntemlerden oluşan formal dil kadar, heterodoks iktisata itilen iktisatçılar tarafindan kullanılan terminoloji, dil farklıdır, özgündür ve karmaşıktır.

\section{Sonuç}

İktisat yazınında hegamonik temelli “makro politika uzlaşı” süreci küresel bir vizyona bağlanmakta, yerleşik uzlaşı yöntemsel positivist metodolojiler içinde analiz yapmaktadır. İktisat bilimi kuramsal ve politika performansı açısından kısa dönemde "muhalif uzlaşılar", içinde ilerlerken, uzun dönemde hızla "yerleşik uzlaşı" menzilinde kurumsallaşmaktadır. Muhalif uzlaşılar, yöntemsel ve politika farkl1lıklarıyla birlikte, yerleşik iktisata doğru yerçekimi etkisiyle uzlaştırılırken, farklı makroiktisadi dinamikler karşısında politika refleksini kaybetme tehlikesiyle karşıkarşıya kalmaktadır. Görünmez el analojisinde olduğu gibi iktisat kuramı, ad hoc varsayımlara dayanan kuramlar eşliğinde, uzun dönemde denge temelli yerleşik uzlaşı yaklaşımına doğru uyumlanmaktadır. Genel olarak iktisat kuramı, yerleşik gelenek, giderek çoğulcu unsurlarını kaybetmekte, tekil bir politika setine dayalı, dar bir stratejiye hapsolmaktadır.

İktisat yazınında kuramların özerkliğini devrederek (Keynesyen iktisat) ya da koruyarak yeni bir uzlaşı deneyimine (yeni makro uzlaşı) evrilme süreci, yerleşik iktisada kuramsal, yöntemsel ve politik bir uzlaşı görünümü kazandırmaktadır. Ancak bu süreç, yeni uzlaşı yaklaşımının varsayımsal tutarlılık ve bütünlük, kuramsal gerçekçilik ve politika performansı açısından göreli olarak etkinlik alanını zayıflatmaktadır. Yerleşik uzlaşı kuramının yeni politika önermeleri ve yerleşik iktisatda uzlaşan kuramların politika önermeleri, piyasada farklı politika tepkileri, farklı makroiktisadi dinamikler üretmektedir.

Yeni uzlaşı kuramı ve kapsadığı kuramlar seti ekonomide farklı dinamikler ve politika tepkileri üretmektedir. Sentez kuramın politika performansı karşısında, piyasada: firmalar, kamu, merkez bankaları gibi organizasyonel kurumlar ile üretim, tüketim, yatırım, tasarruf ve borçlanma gibi davranışsal kurumlar tarafından verilen politika tepkileri, yeni makroiktisadi dinamiklerin kaynă̆ıdır. Kuram tarafından göz ardı edilen, doğru zamanda ortaya konulamayan politika tepkileri karşısında, aktörler son derece rasyonel, ancak, formal yada informal formda maksimizasyon koşullarında optimizasyon seçenekleri yakalama firsatı kazanmaktadır. Ekonomide iktisat bilimi ve politika yapıcılar tarafından ön görülemeyen, kuram dışı davranış olasılığı her zaman mümkündür. Yeni yerleşik uzlaşı kuramı ve uzlaşan kuramlar tarafindan göz ardı edilen kompleks dünya, her koşulda bir realite olarak, piyasalar tarafindan formal ya da informal pozisyonlara firsat yaratarak, küresel kurumsal ortama yön vermektedir. Ancak, uzlaşı kuramının tüm bu dinamikler karşısında yeni bir politika stratejisi ortaya koyabilecek yöntemsel güç, gelişen makro dinamiklere uyum sağlayarak, çözüm üretebilecek, varsayımlar setiyle sağlanacaktır. 
Yerleşik uzlaşı iktisadının her koşulda neoklasik bağlamda kalma eğiliminden uzaklaşarak, çoğulcu yaklaşıma sempatiyle yaklaşması kaçınılmaz bir gerçektir.

Uygulamalı iktisat kendi problematiği dışında hatta kullanılan modelleme tekniği dışında kalan iktisadi sorunla ilgili değildir. Yerleşik uzlaşı modellerinin kuramsal bölümleri, modellerin tercih nedenin açıklandığı, modelin performansının değerlendirildiği giriş bölümleridir. $\mathrm{Bu}$ durumda modellemelerle ulaşılan bulgular, dahası bulgulara ulaşmakta izlenilen yöntemler, kuramcılar tarafından, hatta farklı modellerle çalışan iktisatçılar tarafından çözümlenemeyecek karmaşıklıktadır. Benzer şekilde, iktisadi düşünce analistleri tarafindan yapılan kuramsal ve metodolojik tartışmalar, terminoloji, modelle çalışan çevreler tarafından kolayca zaman ayırılmayacak, anlaşılmayacak derinliktedir. Yerleşik iktisat ya da yerleşik iktisat içinde tercih edilen model dışında kalan iktisat yaklaşımları farklı bir bağlamın ürünüdür. Giderek yerleşik uzlaşı iktisadı ve iktisatçılar kendi bağlamına kilitlenmekte, farklı yaklaşımların modellerin bağlamına girmekte güçlük çekmektedir. Bu durum, iktisat kuramının bütüncül yaklamla analizden mahrum brakmakta, iktisada, kurama parçalı bir görüntü vermektedir.

Yerleşik iktisadın yöntemsel bireyci analitiği, kuramsal bağlamda ayrıştıran, bağlamdan koparan yöntemsel açıdan tekilleştiren bir içerikle yol almaktadır. Kuramı sosyal bağlamdan ve realiteden ayrıştırmaktadır. Makro uzlaşı iktisadının ekonomi politiği, iktisat kurumu tarafından denetlenerek, düzenlenemeyen küresel oyuncular ve küresel piyasalar tarafından üretilmektedir. Gerçekte iktisat kuramının tanıyamadığı, üzerinde politika geliştiremediği bir iktisat kurumu, sistemde yerini güçlendirmektedir. Esasında iktisat kuramı iktisat kurumunu denetleyerek düzenleyecek politika performansından, menzilinden hızla uzaklaşmaktadır. Sistemi denetleyen ve düzenleyen liberal söylemin görünmez el metaforu değildir. Küresel system, yerleşik kuramın neden olduğu informal kurumsal bağlamın, göz ardı edilen davranışsal ve organizasyonel aktörleri (kurumları) tarafından düzenlenmektedir.

\section{Kaynaklar}

Akerlof, G. \& J. Yellen (1985), “A near-rational model of the business cycle with wage and price inertia", Quarterly Journal of Economics, 100 (supp), 823-838.

Arestis, P. (ed.) (2007), Is there a New Consensus in Macroeconomics?, Basingstoke: Palgrave Macmillan.

Aspromourgos, T. (1986), "On the Origins of the Term 'Neoclassical”", Cambridge Journal of Economics, 10(3): 265-70.

Ball, L. \& D. Romer (1991), "Sticky Prices as Coordination Failure”, American Economic Review, American Economic Association, Vol. 81(3), June, 539-52.

Bernanke, B.S. (2000), Essays on the Great Depression, Princeton: Princeton University Press, ISBN 978-0-691-01698-6. 
Blanchard, O.J. (1987), "Neoclassical Synthesis", In: John Eatwell, Murray Milgate and Peter Newman (eds.), The New Palgrave: A Dictionary of Economics, vol. 3. London: Macmillan, 634-6.

Blanchard, O.J. (2008), "The State of Macro”, NBER Working Paper, 14259, August.

Blanchard, O.J. (2009), “The Crisis: Basic Mechanisms and Appropriate Policies”, CESIfo Forum, no. 1, 3-14.

Blanchard, O.J. \& J. Galí (2007), "The Macroeconomic Effects of Oil Shocks: Why Are the 2000s so Different from the 1970s", NBER Working Paper, 13368, September.

Blinder, A. (2010), “Teaching Macro Principles after the Financial Crisis”, Working Paper, № 1222 , Princeton University, Department of Economics, Center for Economic Policy Studies.

Buiter, W. (2009), “The Unfortunate Uselessness of Most 'State of the Art' Academic Monetary Economics", March 3. Blog de Financial Times, 3 de marzo.

Caballero, R.J. (2010), "Macroeconomics after the Crisis: Time to deal with the Pretense-ofKnowledge Syndrome", NBER Working Paper Series, No. 16429, October.

Campbell, J.Y. \& N.G. Mankiw (1990), "Permanent Income, Current Income, and Consumption", Journal of Business \& Economic Statistics, American Statistical Association, vol. 8(3), 265-79, July.

Chari, V. \& P. Kehoe (2006), "Modern Macroeconomics in Practice: How Theory Is Shaping Policy", Journal of Economic Perspectives, Vol. 20, $\mathrm{N}^{\circ}$ 4, 3-28.

Clower, R.W. (1965), "The Keynesian Counter-Revolution: A Theoretical Appraisal”, in: F.H. Hahn and F.P.R. Brechling (eds.), The Theory of Interest Rates, Macmillan. Reprinted in Clower, 1987, Money and Markets, 34-58.

Cochrane, J.H. (2009), How did Paul Krugman get it so Wrong?, <http://faculty.chicagobooth.edu/john.cochrane/research/papers/krugman_response.htm> , 12.08.2015.

Colander, D. (2009), "How Did Macro Theory Get So Far off Track, and what Can Heterodox Macroeconomists Do to Get it Back On Track", Middlebury College Economics Discussion Paper, NO. 09-11, August.

Colander, D. (2006), Post Walrasian Macroeconomics: Beyond the Dynamic Stochastic General Equilibrium Model, Cambridge, UK. Cambridge University Press.

Cooper, R. \& A. John (1988), "Coordinat-ing Coordination Failures in Keynesian Models”, Quarterly Journal of Economics, August, 103, 441-63.

De Grauwe, P. (2009), “Top-Down versus Bottom-Up Macroeconomics”, VoxEurope, November 19.

De Grauwe, P. (2010), “Top-Down versus Bottom-Up Macroeconomics”, CESifo Economic Studies, 56, 465-497.

De Grauwe, P. \& P.R. Kaltwasser (2012), “Animal spirits in the foreign exchange market”, Journal of Economic Dynamics and Control, <http://dx.doi.org/10.1016/j.jedc.2012.03.008>.

De Vroey, M. \& G.P. Duarte (2012), "In Search of Lost of Time: The Neoclassical Synthesis", FEA/USP Pedro Working Paper Series, No 2012-07.

Eichengreen, B. (2009), The Last Temptation of Risk, The National Interest, May/June, <http://www.nationalinterest.org/Article.aspx?id=2127>, 22.06.2015. 
Fischer, S. (1977), "Long-term Contracts, Rational Expectations, and the Optimal Money Supply Rule", Journal of Political Economy, 85: February, no. 1, 191-205.

Friedman, M. (1968), “The Role of Monetary Policy”, The American Economic Review, Vol. 58, March, Number 1.

Goodfriend, M. (2004), "Monetary Policy in the New Neoclassical Synthesis: A Primer”, Economic Quarterly, Federal Reserve Bank of Richmond 90 (3): 21-45.

Goodfriend, M. (2007), "How the World Achieved Consensus on Monetary Policy", Journal of Economic Perspectives, 21(4): 47-68.

Goodfriend, M. \& R.G. King (1997), "The New Neoclassical Synthesis and the Role of Monetary Policy”, NBER Macroeconomics Annual, NBER Chapters (National Bureau of Economic Research) 12: 231-83, JSTOR 3585232.

Gordon, R.J. (2009), "Is Modern Macro or 1978-era Macro More Relevant to the Understanding of Current Economic Crisis", Revision of a paper first presented to International Colloquium on the History of Economic Thought, Sao Paulo, Brazil, August 3, 2009.

Hicks, J. (1939), Value and Capital, 1st ed. Oxford: Clarendon Press.

Hodgson, G.M. (2012), "On the Complexity of Economic Reality and the History of the use of Mathematics in Economics", Filosofía de la Economía, Vol. 1, Nro. 1, Julio 2013, 25-45.

Hodgson, G. (2009), “The Great Crash of 2008 and The Reform of Economics”, Cambridge Journal of Economics, 2009, 33, 1205-1221, Advance Access Publication 17 August.

Hodgson, G. (2011), "The Eclipse of the Uncertainty Concept in Mainstream Economics", Journal of Economic Issues, 45(1), 159-75.

Howit, P. \& A. Kirman \& A. Leijonhufvud \& P. Mehrling \& D. Colander (2008), "Beyond DSGE Models: Towards an Empirically Based Macroeconomics", Middlebury College Economics Discussion Paper, Nㅜㅇ.

Howitt, P. (1987), “Macroeconomics: Relation with Microeconomics”, In: John Eatwell, Murray Milgate, and Peter Newman (eds.), The New Palgrave: A Dictionary of Economics, vol. 3. London: MacMillan, 273-5.

King, M. (1997), "Changes in UK Monetary Policy: Rules and Discretion in Practice”, Journal of Monetary Economics, June 1997, 81-97.

King, M. (1997), “The Institutions of Monetary Policy”, American Economic Review, May 2004, 113.

Krugman, P. (2009a), “The Economist quotes Paul Krugman's LSE Lionel Robbins Lecture of 10 Lehma", June.

Krugman, P. (2009b), “How Did Economists Get It So Wrong?”, New York Times, September, 6.

Landreth, H. \& D. Colander (2002), History of Economic Thought, Boston: Houghton Mifflin Company, capítols 4, 5, 7 i 10.

Lawson, T. (1997), Economics and Reality, Londres y Nueva York: Routledge.

Lucas, R. \& T. Sargent (1978), “After Keynesian Macroeconomics”, The Federal Reserve Bank of Boston Conference Series, Proceedings of a Conference held at Edgartown, Massachusetts, 49-71. 
Lucas, R.E. Jr. ([1980] 1981), "Methods and Problems in Business Cycle Theory", In: Robert Lucas, Studies in Business Cycle Theory, Cambridge (Mass.): The M.I.T. Press, 271-96.

Mankiw, N.G. (2010), "New Keynesian Economics”, The Concise Encyclopedia of Economics, Library of Economics and Liberty.

Mankiw, N.G. (1985), "Small Menu Costs and Large Business Cycles: A Macroeconomic Model of Monopoly", Quarterly Journal of Economics, 100(2), 529-37.

Mankiw, N.G. (2006), "The Macroeconomist as Scientist and Engineer”, Journal of Economic Perspectives, 20(4), Fall, 29-46.

Mendoza, W.B. (2013), "J.M.Keynes, Neoclassical Synthesis, New Neoclassical Synthesis and Crisis: The Current State of Macro economic Theory", Documento Detrabajo, No: 354. <http://www.pucp.edu.pe/departamento/economia/images/documentos/DDD354.pdf.>, 19.06.2015.

Meyer, L.H. (2001), “Does Money Matter?”, Federal Reserve Bank of St Louse Review, May: 1-16.

Orhan, S. (2016), Godot'u Beklerken, J.M.Keynes ve Keynesyenler, İletişim Yayınları.

Patinkin, D. (1956), Money, Interest and Prices, 1st ed. New York: Harper and Row.

Roubini, N. (2009), The Thinkers Who Predicted Early on Many Aspects of this Financial Crisis, May 1, <http://www.rgemonitor.com/roubini-monitor/256589/>, 17.08.2015.

Samuelson, P.A. (1947), Foundations of Economic Analysis, Cambridge (Mass.): Harvard University Press.

Samuelson, P. (1955), Economics, 3rd edn., New York: McGraw-Hill.

Samuelson, P.A. ([1963] 1966), “A Brief Survey of Post-Keynesian Developments”, In: Joseph E. Stiglitz (ed.), The Collected Scientific Papers of Paul A. Samuelson, vol. 2. Cambridge (Mass.): The MIT Press, 1534-50.

Smets, F.R. \& R. Wouters (2003), “An Estimated Dynamic Stochastic General Equilibrium Model of the Euro Area", Journal of the European Economics Association, 1(5): 1123-1175.

Smets, F.R. \& R. Wouters (2007), "Shocks and Frictions in US Business Cycles: A Bayesian DSGE Approach", American Economic Review, 97(3): 586-606.

Solow, R.M. (2008), “Comment”, Journal of Economic Perspectives, 22(1): 243-246.

Solow, R.M. (2010), "Building a Science of Economics for the Real World", A statement for the House Committee on Science and Technology Subcommittee on Investigations and Oversight, 20th July.

Stiglitz, J.E. (2009), “The Current Economic Crisis and Lessons for Economic Theory”, Eastern Economic Journal, 35, 281-296.

Taylor, J. (1980), “Aggregate Dynamics and Staggered Contracts”, Journal of Political Economy, 88: February, no. 1, 1-24.

Veblen, T. (1900), "Preconceptions of Economic Science", Quarterly Journal of Economics, Vol. 14, February, 261.

Woodford, M. (1999), "Revolution and Evolution in Twentieth Century Macroeconomics", Frontiers of the Mind in the Twenty-First Century, U.S. Library of Congress, Washington, D.C., June, <http://www.columbia.edu/ mw2230/>, 28.08.2015. 
Orhan, S.S. (2016), "Modern Makroiktisadi Uzlaşının Kayıp Ekonomi Politiği: Yerleşik Formalist, Yerleşik Kuramsal ve Yerleşik Politik Uzlaşı”, Sosyoekonomi, Vol. 24(27), 139-160.

Woodford, M. (2009), "Convergence in Macroeconomics: Elements of the New Synthesis", American Economic Journal: Macroeconomics, 1(1), January, 267-279. 